\title{
CORRESPONDENCE
}

\section{Postdoc glut means academic pathway needs an overhaul}

\section{SIR - In his Correspondence}

'Fewer academics are not the answer to funding woes' (Nature 454, 397; 2008), Philip Strange suggests that we need to increase the number of trained scientists to help deal with current and future crises such as climate change. But, according to the US National Science Board's Science and Engineering Indicators 2008 (www.nsf.gov/statistics/ seind08), fewer than $20 \%$ of postdoctoral scientists in the United States find tenure-track faculty positions. This suggests that, at least in the United States, we could already have a glut of trained scientists.

Perhaps the solution is not financial at its core at all. A major overhaul of the academic training pathway for life-scientists is long overdue. Issues linked to today's financial and job markets are an indicator that the time is right for a serious self-appraisal on the part of academia. Are we training too many students? And what should we do with all the postdocs?

Ian M. Brooks UTHSC Postdoctoral Association, and Department of Pharmacology, University of Tennessee Health Science Center, Memphis,

Tennessee 38163, USA

e-mail: ibrooks1@utmem.edu

\section{Olympics may have a negative impact on China's research}

SIR - Your Editorial 'China's challenges' (Nature 454, 367-368; 2008) and News Feature 'Visions of China' (Nature 454, 384-387; 2008) proclaim China's increasing strength in science and technology. But this summer's Olympics Games in Beijing may cast a shadow over that landscape.

The Chinese government's investment in the 2008
Beijing Olympics is reflected in a wide range of technical accomplishments. These include the design and construction of the venues, development of energy-saving technology, communication support, comprehensive services for the media, public information and weather forecasting, advanced safety and security, and rigorous drug testing.

But away from the extravagant displays of the opening ceremony, scientists in China are experiencing some negative effects that could take hold in the wake of the Olympics. Nationwide security restrictions on the transport of liquids, for example, have delayed the delivery of chemical and biological reagents to laboratories, especially those coming from abroad. The resources of the entire country have been tapped, draining funds from fields outside Olympic interests. Add to this the cost of the recent earthquakes in Sichuan, and it will become even harder to meet the Chinese state's optimistic goals for research and development.

The post-Olympic era is likely to see more emphasis on disciplines such as Earth science and environmental protection, but considerably less on other areas of science and technology. Yijun Chen, Nan Liu Laboratory of Chemical Biology, China Pharmaceutical University, Nanjing, Jiangsu 210009, China e-mail:yjchen@cpu.edu.cn

\section{Changes in the rules now governing Italy's drug industry}

SIR - I was surprised and dismayed that your Editorial 'Clean hands, please' (Nature 454, $667 ; 2008$ ) should be so careless with the evidence in addressing the question of relations between the government and the pharmaceutical industry in Italy.

In Italy, the pharmaceutical industry is obliged to maintain the lowest prices in Europe. The new government has left these regulations unaltered in its economic programme for the next three years.

At the time of the unfortunate events of the Duilio Poggiolini era 15 years ago, Italy's per capita spending on pharmaceuticals was slightly below the European average. This spending has today fallen to $€ 194$ (US\$290), against a European average of $€ 270-$ even though Italy has easier access to therapies than many other European countries and has more elderly citizens than any of them.

In the past seven years, governments of various political colours have made 18 separate cutbacks on pharmaceutical spending. The 30\% difference from the European average indicates that our industry has not enjoyed government favours.

The pharmaceutical industry has nevertheless fought back against this difficult situation. Its exports have risen from $10 \%$ of total production to $53 \%$, and today it boasts a surplus in its trade balance for medicines.

The replacement of the manager of the Italian medicines agency AIFA, as mentioned in your Editorial, occurred after a judicial enquiry. This was ratified by an independent judicial decision.

The pharmaceutical industry in Italy is represented by an association that belongs to the Italian employers' federation Confindustria. This association has implemented rigorous ethical rules to govern its members' conduct and, in representing the interests of the industry vis-à-vis the public institutions, totally respects their autonomy. Its sole request is that public institutions provide a regulatory framework that is fixed over time and can guarantee timescales and procedures in their authorization processes, in the same way as those in force in other European countries.

Sergio Dompé Farmindustria, Largo del Nazareno 3, 00187 Roma, Italy e-mail:morelli@farmindustria.it

\section{Atheism could be science's contribution to religion}

SIR - We were perplexed by your Editorial on the work of the Templeton Foundation ('Templeton's legacy' Nature 454, 253-254; 2008). Surely science is about finding material explanations of the world explanations that can inspire those spooky feelings of awe, wonder and reverence in the hyper-evolved human brain.

Religion, on the other hand, is about humans thinking that awe, wonder and reverence are the clue to understanding a God-built Universe. (The same is true of religion's poor cousin, 'spirituality', which you slip into your Editorial rather as a creationist uses 'intelligent design'.) There is a fundamental conflict here, one that can never be reconciled until all religions cease making claims about the nature of reality.

The scientific study of religion is indeed full of big questions that need to be addressed, such as why belief in religion is negatively correlated with an acceptance of evolution. One could consider psychological studies of why humans are superstitious and believe impossible things, and comparative sociological studies of religion using materialist explanations of the rise and fall of the world's belief systems.

Perhaps the Templeton Foundation is thinking of funding such research. The outcome of such work, we predict, will not bring science and religion (or 'spirituality') any closer to one another. You suggest that science may bring about "advances in theological thinking". In reality, the only contribution that science can make to the ideas of religion is atheism.

Matthew Cobb Faculty of Life Sciences, University of Manchester, Oxford Road, Manchester M13 9PL, UK e-mail: cobb@manchester.ac.uk Jerry Coyne Department of Ecology and Evolution, The University of Chicago, Chicago, Illinois 60637, USA 